\title{
INVESTIGATION OF IMPACT OF TECHNOLOGICAL PARAMETERS OF COMPRESION ON RELATIVE DENSITY AND MECHANICAL RESISTANCE OF GRANULATED ORGANIC COMPOST FERTILIZERS
}

\author{
Antanas Pocius, Sigute Savickiene, Tytas Savickas, Jurate Vaitekoniene \\ Klaipeda State University of Applied Sciences, Lithuania \\ antan.pocius@gmail.com
}

\begin{abstract}
The main requirement imposed on organic granulated fertilizer as a new product produced from secondary raw material is the possibility to use this product under specific operation conditions determined by environmental factors, static and dynamic loads, mechanical effects, etc. Mechanical strength is considered as the main mechanical property of granulated bulky materials. Organic compost fertilizer pellets as anisotropic materials are characterized by rheological properties which vary in different directions inside the pellet. The study investigated rheological and strength properties of the newly developed granulated organic fertilizer pellets produced from beef cattle and poultry manure and organic waste compost. As a result, the characteristics of mechanical properties of the new product which are characteristic to fragile materials were presented. Dependencies between pellet deformations and the size of the subjected load depending on pellet geometrical parameters were determined and presented by mathematical equations with regression coefficients. Test results have shown that the limit strength in vertical and horizontal directions for organic compost pellets with the diameter of GKM-6 and GM-6 as well as for poultry manure pellet material differed from $10 \%$ to $20 \%$. Pellet mechanical strength depends on their geometric parameters. Elastic modulus of granule material is not constant and depends on the direction of the load subjected to the granule. It has been established that elastic modulus of organic compost granules GKM-6 was $0.43 \pm 0.012$ in the longitudinal direction, and $0.48 \pm 0.03$ in the transverse direction with respect to the granule.
\end{abstract}

Keywords: organic fertilizer pellet, rheological and geometric properties, mechanical strength.

\section{Introduction}

Many of the animal-derived secondary raw materials (manure, feed waste) used for organic fertilizers contain large amount of nitrogen and other nutrients needed for plant growth and development.

The most commonly used organic fertilizer is manure and various types of manure-based compost. Using manure in its natural form (unprocessed) reduces its potential as a fertilizer and causes negative impacts on the environment.

Data from scientific studies showed that storage of manure (as organic fertilizer) and its supposed "maturing" results in decreased value and loss of some dry matter and nutrients. The alleged selfdecontamination effect has also been denied, because the viability of pathogenic microbes and parasites remained higher than it was expected [1-3]. The conditions for storing manure significantly vary, and it is difficult to determine the actual loss of dry matter. Beside the physical and chemical properties of manure, climatic and weather conditions, storage time, frequency of relocation (remixing), etc. are also very important. Losses of organic matter and nitrogen during storage, storage costs - these are the main factors resulting in short storage time of manure.

Moreover, the European Commission has adopted a decision concerning organic fertilizers to be included into the legal frameworks of the European Union.

Non-organic fertilizers remain the major source of nitrogen for arable land in the European Union. Manure as a source of nitrogen remains in the second place, however, the situation differs in different EU countries. In some countries, such as the Netherlands or Belgium, manure represents more than $50 \%$ of the total amount of nitrogen fertilizers required. Approximately $62 \%$ of all organic fertilizers are produced by the following five EU countries: Germany, Italy, France, Spain, Netherlands [4]. The producing countries at the same time are the main users of organic fertilizers.

The objective of recycling livestock waste is to bring these products back into the environment in the form of organic fertilizers without causing adverse effects and at the same time improving the soil by increasing the amount of humus content and improving the soil structure. Such production of organic fertilizers with the desired qualitative indicators can be used for granulating manure and organic compost. The technological process is easily controlled and allows producing a new product with the expected and required features. 
Granulating organic fertilizer results in better physical and agrochemical properties. Fertilizer remains bulky with stacking due to storage prevented, therefore, it is easy to transport and distribute in field using the same mineral fertiliser spreading machines; also suitable for local fertilising. Using this type of fertilizer, nutrients are more efficiently absorbed by plants; dissolution takes place more slowly, and are better spread in the soil resulting in lower fertiliser losses [1;2].

Beside the nutrient content, granulated organic fertiliser must have the following consumerrelevant properties: physical (desired fractional composition, bulkiness, stacking-resistance, having no sharp odor, etc.), mechanical (sufficient static and dynamic strength, mechanical resistance).

Static strength indicator allows predicting what part of the product granules may decompose (chatter) during storage when subjected by force of the mass of the top layers [5;6].

Dynamic strength indicator characterises granule behaviour under impact load (when in contact with the spreading machine working parts, etc.) and is expressed by the percentage of the chattered granules [7].

Mechanical resistance characterises the emerging part of powder fraction when the granule mass is subjected to mechanical impact. This indicator is used to evaluate the loss of mass resulting from relocations of granular product, spreading in soil, etc. [5;7;8]. Mechanical resistance of granules depends on the surface morphological characteristics and the external layer strength. It may be claimed that all the three indicators of strength together characterise the capacity of granulate organic fertiliser to retain its shape and geometrical measurement when subjected to external loads.

Static strength indicator specifically reflects the physical-mechanical properties of granules depending on the granule moisture content [5;6]. Therefore, static strength of granules mostly depends on the parameters of the technological process, product mass composition and moisture content.

Depending on the nature of the force subjected to the granule, the structural-mechanical (rheological) product properties are considered differently. Deformation properties characterize the material volumetric behaviour when granule is under normal and tangential stresses. Deformation properties are important both in dealing with various granule movement processes when transporting, getting into contact with agricultural machinery working parts, and when evaluating the product quality indicators. One of such modules is the granule (new product) elastic modulus. Granule compression properties, which are also characterized by the elastic modulus, are required when calculating and designing machine or equipment working parts.

Granular product surface properties (adhesion, external friction) characterize granule external surface behaviour when in contact with other possible working surfaces (machinery, storage equipment, etc.) or other materials.

Material rheological properties (characteristics) determine the possible operating conditions for the product in question (granules). The impact of these properties is significant for various aspects from the technological parameters of production to determining the product quality indicators.

\section{Materials and methods}

During granulation a dispersed structure is formed with respective graininess, compression density, phase contacts between individual particles, and persistence as well as certain internal defects of various nature. The character of the formed granule determines the mechanical strength, hydroscopy and other quality parameters of granules.

The velocity of granule passing through the matrix channel depends on the compression pressure of the granulator, geometrical parameters of the matrix, and on the properties of the organic material being compressed. Assuming the laminar character of the material flow along the matrix channel, the granule velocity is expressed as follows [7;9]:

$$
v=\sqrt{\frac{2}{\gamma_{g r}}\left(P \cdot e^{\frac{4 f_{m} \varsigma}{d} l}+\frac{p_{a}}{\varsigma}\left(e^{\frac{4 f_{m} \varsigma}{d} l}-1\right)\right)},
$$

where $\quad v$-granule velocity, $\mathrm{m} \cdot \mathrm{s}^{-1}$;

$e$ - material relative deformation; 


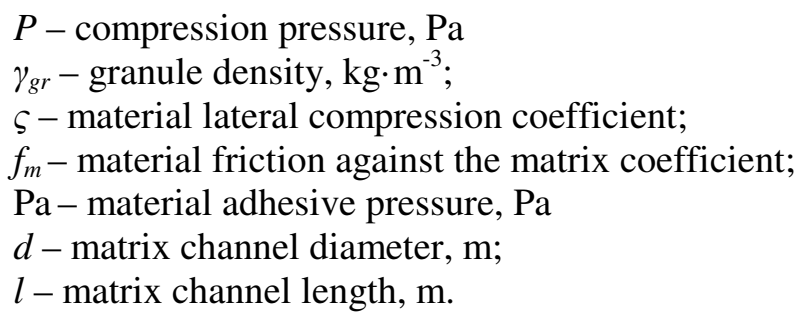

During compression the relationship between the relative deformation $e$ and the material porosity coefficient can be expressed by the following dependence of geometrical character [9]:

$$
e=\frac{\varepsilon_{c}-\varepsilon}{1+\varepsilon_{c}},
$$

where $\varepsilon_{c}$ - initial porosity coefficient;

$\varepsilon$ - porosity coefficient when subjected to pressure $P$.

Material relative density $\varepsilon$ is determined as follows:

$$
\varepsilon=\frac{\rho_{m}}{\gamma(1-W)}-1,
$$

where $\rho_{m}$-solid phase density of the material, $\mathrm{kg} \cdot \mathrm{m}^{-3}$;

$\gamma$ - bulk density of the material, $\mathrm{kg} \cdot \mathrm{m}^{-3}$;

$W$ - relative humidity.

Theoretical formulas contain series of empirical coefficients, which requires experimental evaluation. In order to have specific numerical values for calculations, experimental tests require determining physical-mechanical and rheological properties of materials and the values of specific coefficients.

Structural-mechanical product properties characterise granule behaviour when granule is subjected to load and allow determining the relationship between the emerging stress and deformations.

$$
\Delta l=F l / E A,
$$

The main variables that characterize the behaviour of the material being deformed are deformation and the speed of deformations. The relationship between the force stress characteristics and these variables sufficiently characterizes the rheological properties of the material. In case of small deformations of solid objects, the rheological character of material can be explained by Hooke's law.

For axial deformation this relationship is expressed as a non-linear function $(\varepsilon=f(\sigma, t))$. These characteristics are not fixed constants for material, and mostly depend on the shape of the granule, its geometrical measurements, structure, load speed, environmental impacts and other factors.

The rheological properties of composite material (mixture) are influenced by the properties of its structural elements (tendency to deform, strength, etc.), peculiarities of the movement of the elements (direction, character of motion), and their interconnection in the mixture (strength, moisture absorption, etc.).

The main rheological properties of granules involve elasticity, plasticity, and strength. Elasticity is understood as a property of granule to completely restore its former shape and volume after deformation, when the deformation activity is equal to the recovery activity. This property is characterised by the elastic modulus $\mathrm{E}$ of material.

The amount, dimensions and concentration of existing structural defects (cracks, pores) in the volume of granule affect its structural-mechanical properties (Fig. 1).

Internal stresses inside the granule can not only cause its deformation (both elastic and plastic), but also disintegration of individual parts in the granule structure, i.e. be the cause for its decreased strength. 
a)

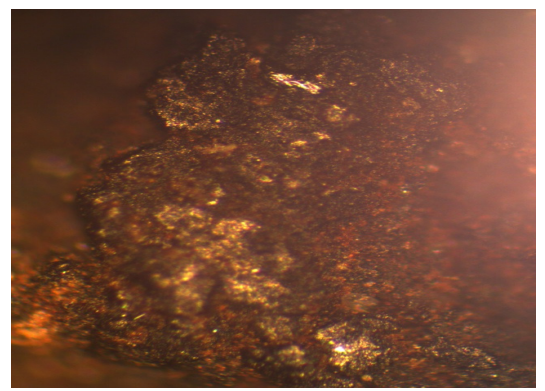

b)

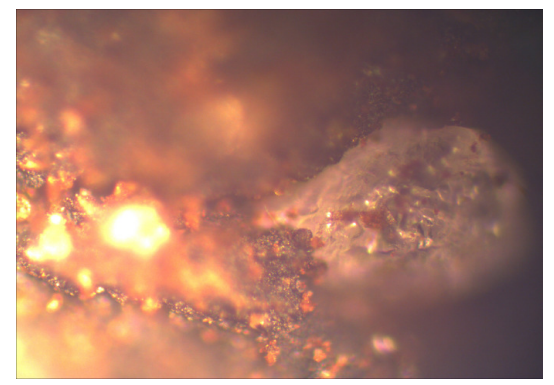

Fig. 1. Granule fractional composition: $\mathrm{a}$ - longitudinal section; $\mathrm{b}$ - cross-section

As the subject of study, organic compost and ordinary biohumus granulated fertilisers produced of cattle manure and feed waste using a special technology were selected. Compost preparation technology, its composition in percentages, is the property of the company engaged in this business, therefore the product was assigned a code name GKT. The fertilizers were granulated using a horizontal matrix equipped with the channels having the diameters of $6 \mathrm{~mm}$ and $4 \mathrm{~mm}$. The physical parameters of organic granulated fertilizers are presented in Table 1.

Table 1

\section{Physical parameters of granules}

\begin{tabular}{|c|c|c|c|}
\hline \multirow{2}{*}{ Parameters } & \multicolumn{2}{|c|}{ Granules } & \multirow{2}{*}{ Methods } \\
\cline { 2 - 3 } & GKT-6 & GM-6 & \\
\hline Humidity, $\%$ & $16.41 \pm 0.32$ & $14.86 \pm 0.44$ & LST EN 14474:2010 \\
\hline Bulk density, $\mathrm{kg} \cdot \mathrm{m}^{-3}$ & $769.9 \pm 4.71$ & $786.36 \pm 5.81$ & LST EN 15103:2010 \\
\hline
\end{tabular}

Static strength of granules was measured by applying compression using uni-directional load until the granule collapsed. The load was increased slowly enough to allow the stresses in the granule to be relieved at the expense of plastic deformations.

To determine the static strength of granule material, a universal testing machine Instron 5960 as well as computer system Bluehill for controlling and recording of test parameters were used. The velocity of static load varied from 0.1 to $10.0 \mathrm{~mm} \cdot \mathrm{min}-1$. Tests were performed by compressing the granules in vertical (load force parallel to the granule's longitudinal axis of symmetry) and horizontal directions. Number of test repetitions was as high as 30 (20 is enough according to the methodology) [6]. Results of the tests have been processes using mathematical-statistical methods assessing the values of data averages and their confidence intervals given the probability of $95 \%$. The dynamics of the force forming the granule was recorded during each testing. This allowed judging on the deformation character of granules (elastic or plastic).

For testing granules with increased moisture $(95 \%)$ content they were stored in a damp medium for several hours in a desiccator.

Damp samples were isolated for five days for the moisture to distribute in granules evenly. This approach has made it possible to evaluate the impact of moisture on the physical-mechanical properties of the product more reliably. Samples were evaluated for granule deformation.

\section{Results and discussion}

The results of the tests showed that the scope of deformation depends on the granule position, i.e. the geometrical axis (longitudinal or transverse) of the subjected load. Until the load subjected towards granules reaches the maximum value, deformation is evenly distributed along the entire sample length. The character of granule disintegration may be assessed with reference to the force dynamics graph.

When the load reaches the maximum value, deformation is localized in one place. Elastic deformations have been observed to take place inside the granules of organic fertilizers before they collapse, which is characteristic of fragile materials. The dependence between elastic deformation and stresses is non-linear and apparently does not follow the Hook's law. 
The results of the tests showed that, when compressing granules of different diameters in vertical and horizontal directions, the strength of the tested granules up to the maximum static load (maximum normal stresses) varies from $10 \%$ to $20 \%$.

The results of the studies have shown that the elastic modulus $E$ of organic compost granules, which characterizes their resistance to elastic deformation, is not constant and varies within certain limits. It has been established that elastic modulus of organic compost granules GKM-6 was $0.43 \pm 0.012$ in the longitudinal direction, and $0.48 \pm 0.03$ in the transverse direction with respect to the granule.

a)

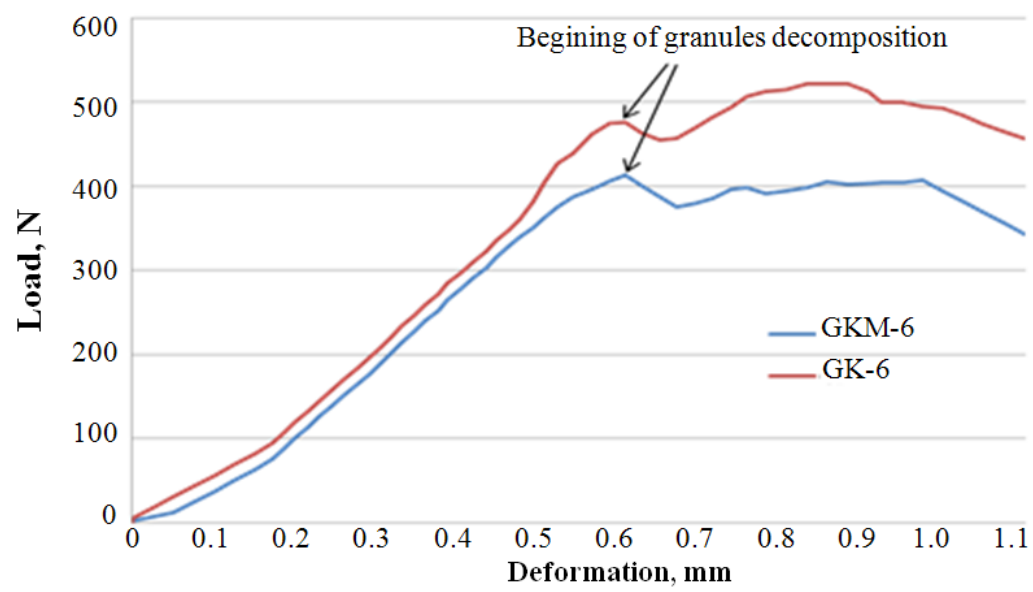

b)

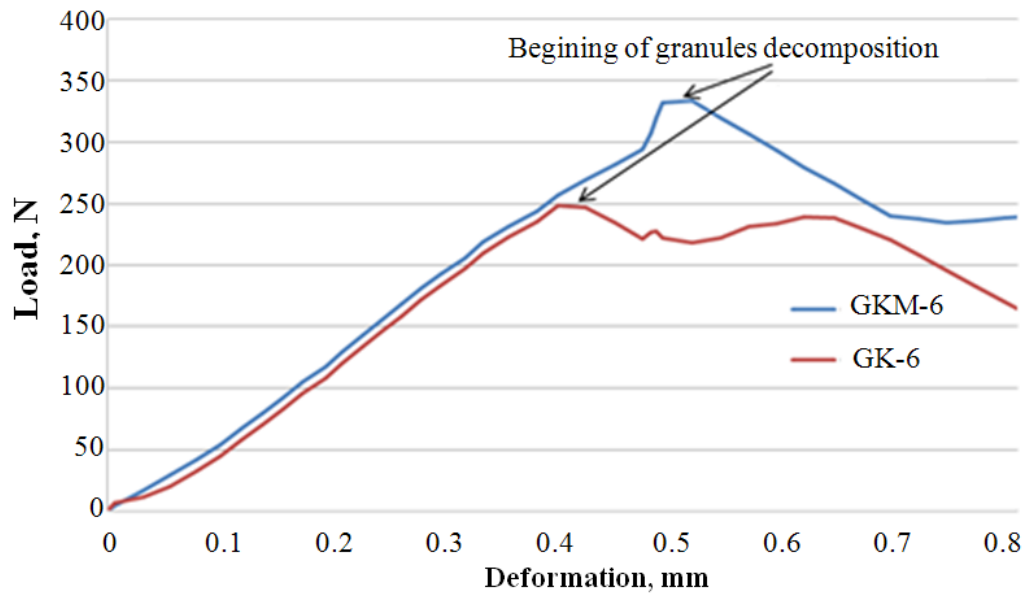

Fig. 2. Granule dependence from deformation on load:

$\mathrm{a}$ - vertical compression; $\mathrm{b}$ - horizontal compresion

Value EA (formula 4) can be considered as the stiffness of granule. It can be claimed that the stiffness of granule depends on the material characterised by the elastic modulus $E$, and on the crosssectional area of the granule. For the sake of clarity, the concept "relative stiffness" can be assumed, which is expressed as $E A / l=\varepsilon$, i.e. the ratio of stiffness with the length of granule in the direction of the load force.

Experiments show that the process of granule disintegration in longitudinal and transverse directions is not uniform (Fig. 3).

When compression takes place in the longitudinal direction (Fig. 3a), the process of disintegration in the course of deformation is similar to disintegration into separate granule parts. Disintegration of virtually all granules compressed in transversal direction started in vertical (compression) direction. A conclusion can be made about uneven structure of material along the granule length as well as low transversal deformation of material (granule). This characterises fragility of the material. This means that the relative deformation action is very low, and the granule capability to absorb the kinetic energy of the impact is relatively low. 
a)

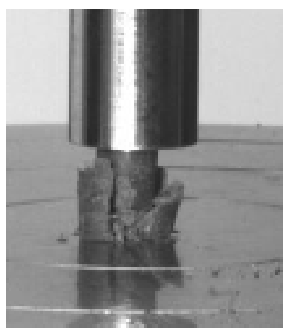

b)

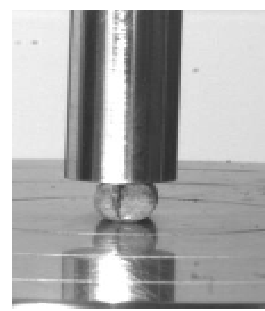

Fig. 3 Visualization of granules with degradation test: $\mathrm{a}$ - longitudinal direction load; $\mathrm{b}$ - cross-section load

The results obtained suggest that the granule disintegration mechanism varies depending on the moisture content and the velocity of the load subjected toward the granule. With increased moisture content the amount of plastic granules increases and the average strength of granules noticeably reduces. Based on the results of the study, it can be concluded that the dependence of the static strength of granules on the moisture content was more pronounced in granules $G K M-6$ compared to that of $G M-6$ granules.

a)

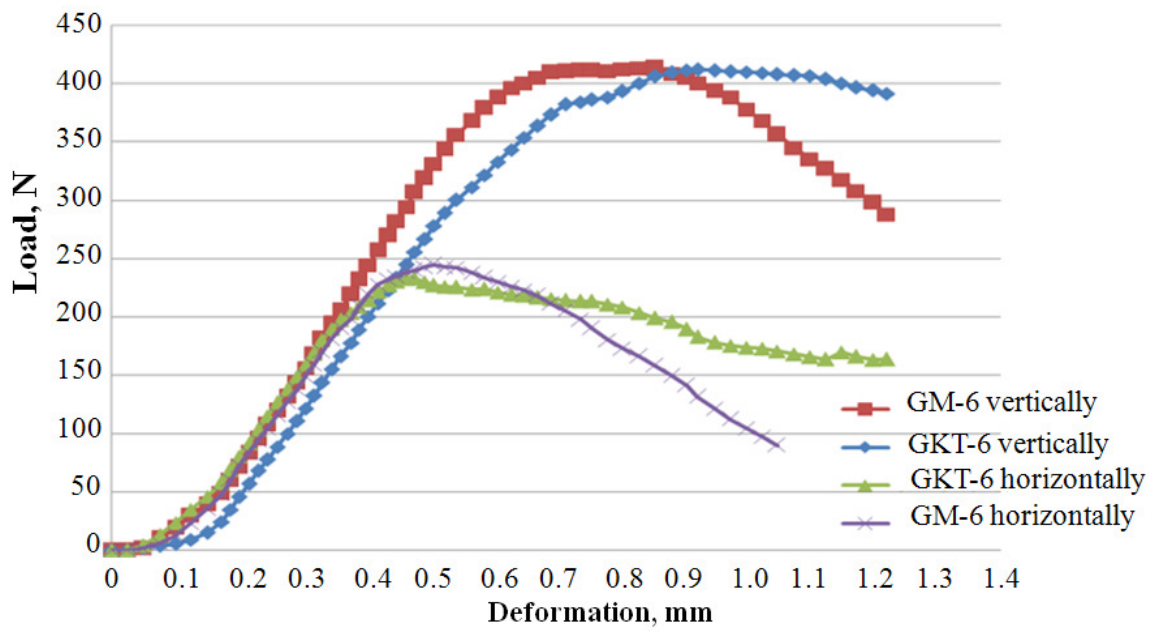

b)

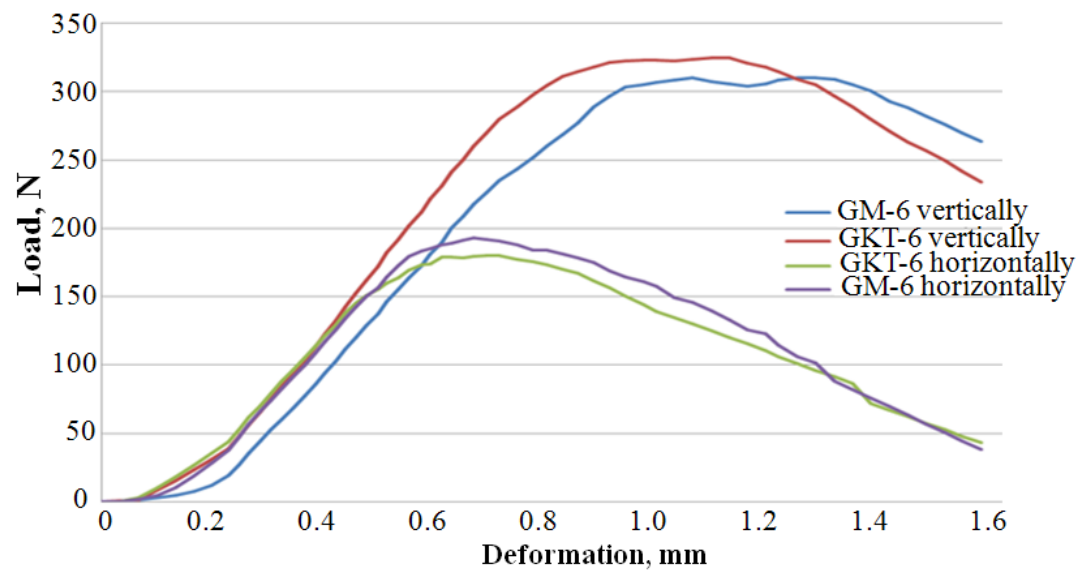

Fig. 4. Granule deformation dependence on humidity (avereges of all deformations tests): a - humidity $W=16 \%$; b - humidity $W=26 \%$

Figure 4 shows granule deformation and disintegration characteristics depending on granule humidity.

Load speed $0.33 \mathrm{~mm} \cdot \mathrm{s}^{-1}$. It can be seen that moist granules have a more expressive "plastic" disintegration character. Granule decomposition occurs in several stages. The maximum load does not always correspond to the beginning of the fragmentation. 
Figure 5 shows the breakdown dynamics of granules GKM-6 (16,2\% moisture) with a crushing speed of $0.33 \mathrm{~mm} \cdot \mathrm{s}^{-1}$ and $1.5 \mathrm{~mm} \cdot \mathrm{s}^{-1}$. At a speed of $0.33 \mathrm{~mm} \cdot \mathrm{s}^{-1}$, the force of time is non-linear. This shows the plasticity of the granules.

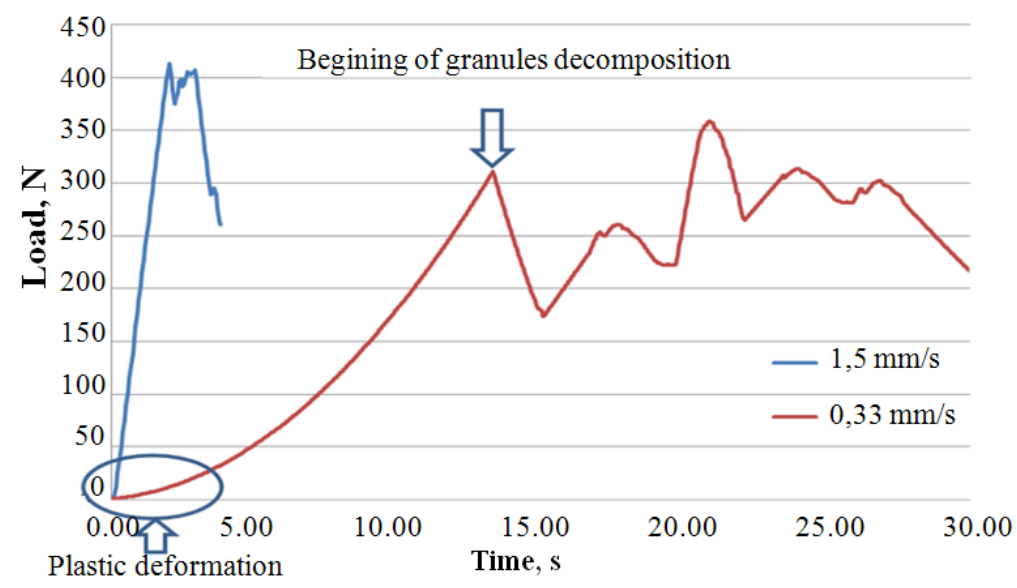

Fig. 5 Granule deformation dependence on load speed

\section{Conclusions}

1. Static strength of granules depends on the technological parameters of the granulation process (diameter of matrix channels) and composition of the mixture being granulated. Elastic modulus of granule material is not constant and depends on the direction of the load subjected to the granule. It has been established that the elastic modulus of organic compost granules GKM- 6 was $0.43 \pm 0.012$ in the longitudinal direction, and $0.48 \pm 0.03$ in the transverse direction with respect to the granule.

2. The process of granule disintegration differs in longitudinal and transversal directions. Stiffness of the studied granulated organic fertilizer depends on the "relative stiffness". As a result, the structure of the material may be claimed to be uneven in the formed granule.

3. The mechanism of granule disintegration depends on the moisture content and velocity of the load subjected to the granule. With increased moisture content, the average strength of granules is significantly reduced (from $15 \%$ to $35 \%$ ). It may be claimed that the state in the material changes from brittle into elastic.

\section{References}

[1] Лер Р. Переработка и использование сельскохозяйственных отходов. (Agricultural waste recycling and utilization). Перевод с анг. В. В. Новикова. - М: Колос, 1979, 415 с. (In Russian).

[2] Pocius A., Jotautiene E., Pekarskas J., Mieldažys R., Jasinskas A. Research of particle geometrical parameters and aerodynamic features of granular organic compost fertilizers// Engineering for rural development : 13th international scientific conference: proceedings, May 29-30, 2014. Jelgava, 2014. ISSN 1691-3043. Vol. 13, pp. 296-300.

[3] Jasinskas A., Pekarskas J., Kucinskas V., Aboltins A. Investigation of natural magnesium mineral fertilizer granulation and determination of granule qualitative indicators. In Engineering for rural development: 15th international scientific conference proceedings, 2016, pp. 647-652.

[4] 2014/955/EU: Commission Decision of 18 December 2014 amending Decision 2000/532/EC on the list of waste pursuant to Directive 2008/98/EC of the European Parliament and of the Council Text with EEA relevance . [online][16.02.2019] Available at: https://publications.europa.eu/en/publication...8ff5.../language-en.

[5] Pocius A., Jotautiene E., Mieldažys R., Jasinskas A., Kucinskas V. Investigation of granulation process parameters influence on granulated fertilizer compost properties // Engineering for rural development: 13th international scientific conference : proceedings, May 29-30, 2014. Jelgava, 2014. ISSN 1691-3043. Vol. 13, pp. 296-300. 
[6] Pocius A., Jotautienė E., Pekarskas J., Palšauskas M. Investigation of physical-mechanical properties of experimental organic granular fertilizers. In Engineering for rural development: 15th international scientific conference proceedings, 2016, pp. 1115-1120.

[7] Завражнов А. И., Николаев Д. И. Механизация приготовления и хранения кормов (Forage preparation and storage mechanization). - М. : Агропромиздат, 1990. - 336 c. (In Russian)

[8] Sirvydis J., Dravininkas A. Dirbtinai džiovintos žolès pašaro ruošimo technologiniai pagrindai (Artificially dried grass forage technological preparation bases.) Monografija. - LŽŪU Žemès ūkio inžinerijos institutas, 2005. - 230 p. (In Lithuanian)

[9] Половцев Е. Л., черкасов А. Н. Производство органических компостов на промышленную основу (Organic compost production for industrial bases) // Механизация и Электрификация сел. хоз-ва. 1992. N0 9 - 12. С. 16 - 18 (In Russian). 